\title{
Numerical simulation for horizontal -spraying -tower flow of wet desulfurization spray tower*
}

\author{
Hai-Jun Tian ${ }^{1,2, \dagger}$, Cun-Yi Song ${ }^{1}$ and Wei Su${ }^{1}$ \\ ${ }^{1}$ School of Civil and Environmental Engineering, University of Science \\ and Technology Beijing, \\ Beijing 100083, China; \\ ${ }^{2}$ College of Resources and Environ BaoTou Teachers' College, \\ Ment Inner Mongolia University of Science and Technology, \\ BaoTou 014030, China \\ 'E-mail:thj8816@126.com
}

\begin{abstract}
Simplified reasonably and modeled large scale desulfurization tower, using the software to build a physical model, using ICEM software to divide the grid, using software fluent 15 to simulate. Selected k-E model as calculating model, SIMPLE algorithm is used to calculate. Calculation results show that horizontal wet desulfurization tower body design of the flue gas absorption region, the influence of flow field and pressure field greatly, at the same time affect the desulfurization slurry and the flue gas mixture reaction. Optimize the absorption area of the desulfurization tower design; it is conducive to improve the efficiency of flue gas desulfurization.
\end{abstract}

Keywords: The Wet Desulfurization; Horizontal Spray Tower; the Software Fluent 15;

\section{Introduction}

Spray tower is the main equipment in wet flue gas desulfurization project [1].According to the flow direction of flue gas; the wet desulfurization tower is divided into vertical and horizontal columns. Vertical tower includes: spraying method [2-3], Grid type [4], Bubble type [5-7], Liquid column [8], etc.

The absorbent used in the wet process horizontal flue gas desulfurization process is the low price of raw lime. After the water is purified and digested into $\mathrm{Ca}(\mathrm{OH})_{2}$, Then mixed with a large number of circulating ash in the bag filter, Wet desulfurization tower is composed of a horizontal upper nozzle into the tower, And react with $\mathrm{SO}_{2}$ that it from the upper left side of the desulfurization tower to enter, the flue gas desulfurization through the mist eliminator to remove droplet, After the flue gas heater heats up, the flue gas is discharged into the atmosphere through the chimney.

\footnotetext{
${ }^{*}$ The authors were grateful to the Iron and Steel Corporation for providing the plant data.
} 
Actual operation shows: The key factors affecting the efficiency of wet flue gas desulfurization tower is a complex flow field[9].For the spray tower, the test method is difficult to reveal alone flow situation in the tower. Using quantitative test and visual display on solid model, further research on the structure parameters of the horizontal wet FGD system and the influence of the compliance with the conditions on the distribution of the flue gas flow field and the concentration distribution of the slurry droplets, to provide practical basis for the design optimization of horizontal wet process parameters

\section{Physical Model}

\subsection{Mock object}

Using CFD numerical simulation, Firstly, the physical model of wet horizontal spray tower is established, and to simplify reasonably model. Horizontal desulfurization tower structure as shown in Figure 1.Horizontal desulfurization tower is rectangular pyramid. Tower body length is $26 \mathrm{~m}$, Height is $9.8 \mathrm{~m}$, the liquid level is $3.4 \mathrm{~m}$, Inlet section of the tower is $3.0 * 5.7 \mathrm{~m}$, the cross section of the tower is $5.7 * 5.7 \mathrm{~m}$. with 5 columns and 8 rows, 40 spiral nozzles are arranged. Figure 1 shows the physical model of A $(5.7 * 6.4 \mathrm{~m}), \mathrm{B}(6.4 * 6.4 \mathrm{~m})$ for the design of two kinds of absorption area, specific parameters are shown in Table 1.

Table 1. Simulation parameters of flue gas.

\begin{tabular}{|c|c|c|c|}
\hline Items & Numerical value & Unit & Remarks \\
\hline Flue gas volume(Q) & $6.0 * 10^{5}$ & $\mathrm{Nm}^{3} / \mathrm{h}$ & \\
\hline Flue gas temperature(T) & 418 & $\mathrm{~K}$ & \\
\hline Smoke density $(\rho)$ & 1250 & $\mathrm{Kg} / \mathrm{m}^{3}$ & \\
\hline Ratio of calcium to sulfur & 1.03 & $\mathrm{~mol} / \mathrm{mol}$ & \\
\hline \multicolumn{4}{|l|}{ Model geometry } \\
\hline Tower shape & \multicolumn{3}{|c|}{ Horizontal } \\
\hline Inlet diffuser length & 4.5 & $\mathrm{~m}$ & Rectangular tube \\
\hline Outlet size $(\mathrm{L} * \mathrm{~W})$ & $5.7 * 5.7$ & $\mathrm{~m}$ & \\
\hline Outlet diffuser length & 1.500 & $\mathrm{~m}$ & Rectangular tube \\
\hline Tower size $(\mathrm{L} * \mathrm{~W} * \mathrm{H})$ & $26 * 5.7 * 9.8$ & $\mathrm{~m}$ & $\mathrm{~A}$ \\
\hline Flue gas inlet size $\left(\mathrm{L}^{*} \mathrm{~W}\right)$ & $5.7 * 3.3$ & $\mathrm{~m}$ & \\
\hline Outlet size(R) & 2.2 & $\mathrm{~m}$ & \\
\hline Tower size $\left(\mathrm{L} * \mathrm{~W}^{*} \mathrm{H}\right)$ & $26 * 6.4 * 9.8$ & $\mathrm{~m}$ & B \\
\hline Size of flue gas outlet $(\mathrm{L} * \mathrm{~W})$ & $6.4 * 6.4$ & $\mathrm{~m}$ & \\
\hline Outlet size(R) & 2.2 & $\mathrm{~m}$ & \\
\hline
\end{tabular}




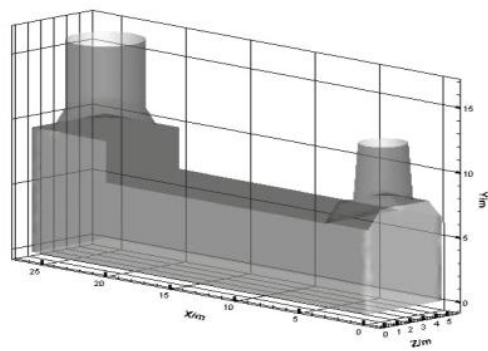

A

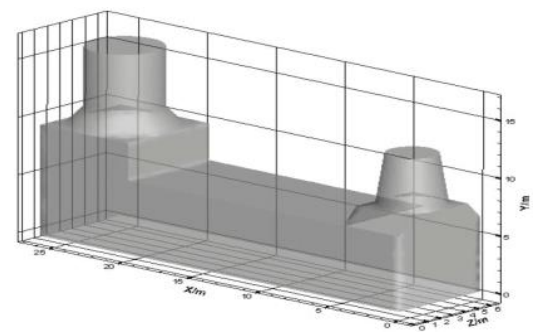

Fig. 1. Design of wet horizontal spray tower with different absorption area.

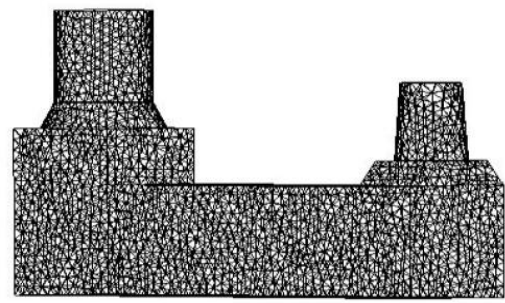

A

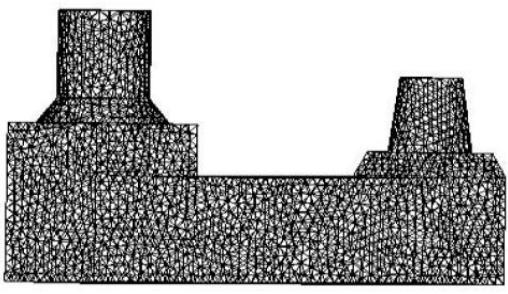

B

Fig. 2. Wet horizontal spray tower in different absorption area.

\subsection{Phsical model}

According to the actual operating environment of WFGD system, the internal smoke flow of the wet horizontal spray tower is assumed as follows:

1)The gas flow is steady and incompressible, and the turbulence is isotropic;

2)Neglecting the effect of gravity on gas flow;

3)Spray tower wall is adiabatic wall;

4)In the calculation, the storage pool is not considered, therefore, it is omitted. And the storage pool of the page as a static liquid.

After the above treatment, only the absorption region of the liquid level is used as the research object.

\subsection{Numerical simulation model}

\subsubsection{Gas phase turbulence model}

Based on the above assumptions, the Reynolds averaged N-S equations, the standard k- turbulence model for gas phase turbulence simulation:

$$
\frac{\partial}{\partial t}(\rho k)+\frac{\partial}{\partial x_{i}}\left(\rho k u_{i}\right)=\frac{\partial}{\partial x_{j}}\left[\left(\mu+\frac{\mu_{t}}{\sigma_{k}}\right) \frac{\partial k}{\partial x_{j}}\right]+P_{K}-\rho \varepsilon
$$


$\frac{\partial}{\partial \mathrm{t}}(\rho \varepsilon)+\frac{\partial}{\partial x_{i}}\left(\rho \varepsilon u_{i}\right)=\frac{\partial}{\partial x_{j}}\left[\left(\mu+\frac{\mu_{t}}{\sigma_{\varepsilon R N G}}\right) \frac{\partial \varepsilon}{\partial x_{j}}\right]+\frac{\varepsilon}{k}\left(C_{\varepsilon 1 R N G} P_{k}-C_{\varepsilon 2 R N G} \rho \varepsilon\right)$ (2)

Where: $C_{1 \varepsilon R N G}=1.42-f_{\eta} ; f_{\eta}=\eta(1-\eta / 4.38) / 1+\beta_{R N G} \eta^{3}$; $\eta=\sqrt{\mathrm{p}_{k} / \rho C_{\mu R N G^{\varepsilon}}} \cdot \mathrm{k}$ is Turbulent kinetic energy, $\mathrm{m}^{2} / \mathrm{s} . \quad \varepsilon$ is Turbulent dissipation factor, $\mathrm{m}^{2} / \mathrm{s}^{3} ; \mu_{\mathrm{t}}$ is Turbulent viscosity coefficient, $\mathrm{Pa} \mathrm{s} ; \mathrm{P}_{\mathrm{k}}$ is Turbulent viscous force; $C_{\mu}=0.09, \sigma_{\mathrm{k}}=1.0, \sigma_{\varepsilon R N G}=0.7179, C_{\varepsilon 2 R N G}=0.012$, $C_{\mu R N G}=0.085$ are iconstants

\subsubsection{Droplet motion model}

Particle transport model is used to determine the gas and particle flow field, the particles were tracked by Lagrange motion. The governing equations of the droplet governing equations are shown to be as follows

$$
\frac{d u_{p}}{d t}=F_{D}\left(u_{g}+u_{p}\right)+\frac{g\left(\rho_{p}-\rho_{g}\right)}{\rho_{p}}
$$

Where: Drag model is Schiller-Naumann. Eq. (4) is Eq. (4) is used to define the drag, Eq. (5) and Eq. (6) are determined by the coefficient of drag coefficient CD.

$$
\begin{gathered}
F_{D}=\frac{18 \mu}{\rho_{P} \mathrm{~d}_{p}^{2}} \frac{C_{D} \mathrm{Re}}{24} \\
C_{D}=\frac{24}{\operatorname{Re}}\left(1+0.15 \operatorname{Re}^{0.687}\right) \\
\operatorname{Re}=\frac{\rho_{p} d_{p}\left|u_{p}-u_{g}\right|}{\mu}
\end{gathered}
$$

Where: $\mathrm{u}$ is droplet velocity, $\mathrm{m} / \mathrm{s} ;{ }^{\rho}$ is Liquid drop concentration, $\mathrm{kg} / \mathrm{m} ; \mu$ is dynamic viscosity, $\mathrm{Pa} \mathrm{s}$; dp is droplet diameter, $\mathrm{m}$.

\subsubsection{Discrete phase model}

$$
\begin{gathered}
F=\sum\left[F_{D}\left(u_{g}-u_{p}+F_{0}\right)\right] m_{p} \Delta t \\
Q=\left[\frac{\overline{m_{p}}}{m_{p, 0}} c_{p} \Delta T_{P}+\frac{\Delta m_{p}}{m_{p, 0}}\left(-h_{f j}+h_{p y r o l}+\int_{T_{r e f}}^{T_{P}} c_{p, i} d T\right)\right] \overline{m_{p, 0}}
\end{gathered}
$$

Where: $\mathrm{F}$ is the force between gas and liquid, $\mathrm{N} ; F_{o}$ is the unit mass force, 
$\mathrm{N} / \mathrm{kg} ; m_{p}$ is mass flow rate of liquid phase, $\mathrm{kg} / \mathrm{s} ; \Delta \mathrm{t}$ is time step, $\mathrm{s} ; h_{f j}$ is the latent heat of vaporization, $\mathrm{J} / \mathrm{kg} ; m_{p}$ is to control the average quality of particles in the body, $\mathrm{kg} ; c_{p}$ is the energy of a particular particle. $\mathrm{J} /(\mathrm{kg} . \mathrm{K}) m_{p, 0}$ is initial particle mass, $\mathrm{kg} ; \Delta T_{P}$ is to control the amount of temperature changes in the body particles, $\mathrm{K} ; h_{\text {pyrol }}$ is the heat required to evaporates $/ \mathrm{kg} ; c_{p, i}$ is the specific heat, $\mathrm{J} / \mathrm{kg}$. K $\Delta m_{p}$ is to control the quantity of liquid drops. $\mathrm{Kg} ; T_{P}$ is controlled by the temperature; $T_{r e f}$ is the reference temperature of enthalpy, $\mathrm{K}$.

\section{Result and Discussion}

\subsection{Internal flow field distribution in a non spray tower}

\subsubsection{Velocity flow field distribution}

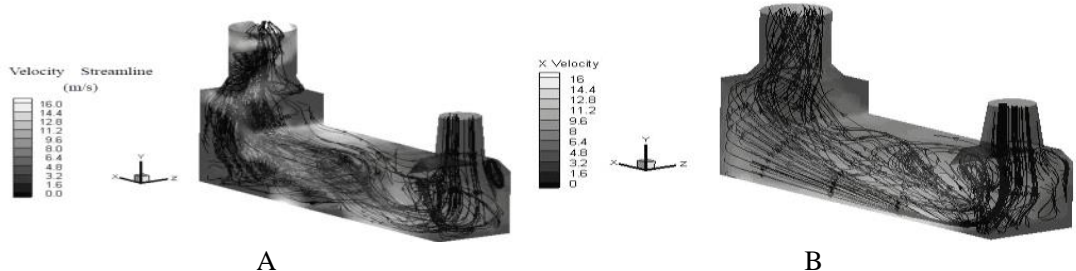

Fig. 3. Different horizontal wet desulfurization tower wide thermal spray state trajectories.

Figure 3 is the spray tower width under different gas flow trajectories. As shown :the flue gas enters the tower downward flow, and after the collision of the liquid level to a movement to the left, in the flue gas into the tower below formed an intense swirling vortices region, forming a instability of the flow field. When the width of the column is increased from $5.7 \mathrm{~m}$ to $6.4 \mathrm{~m}$, from the current cyclotron speed trajectories into the tower below is more severe, the flue gas reflux phenomenon is more and more obvious. the flue gas short circuit is now possible absorption area[10], Which will directly affect the desulfurization efficiency of flue gas.

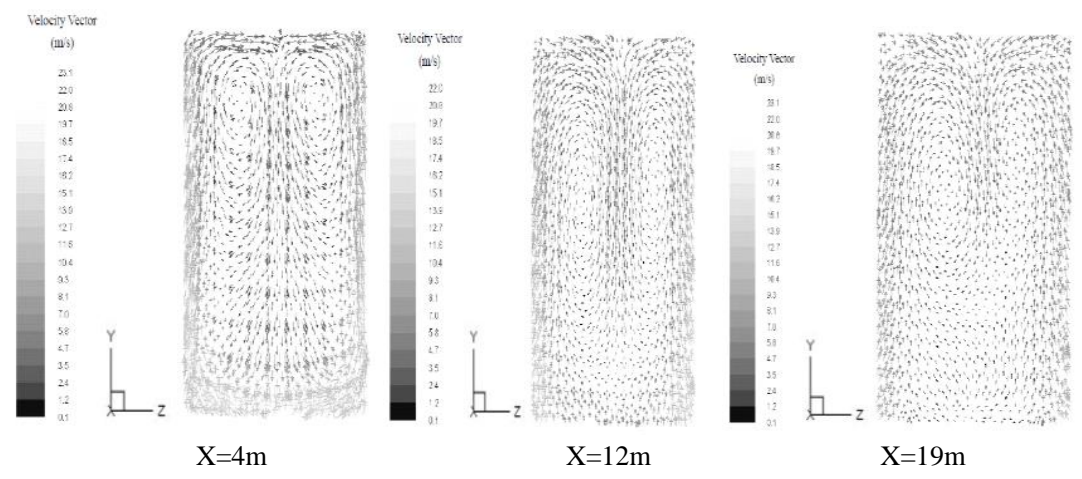


A
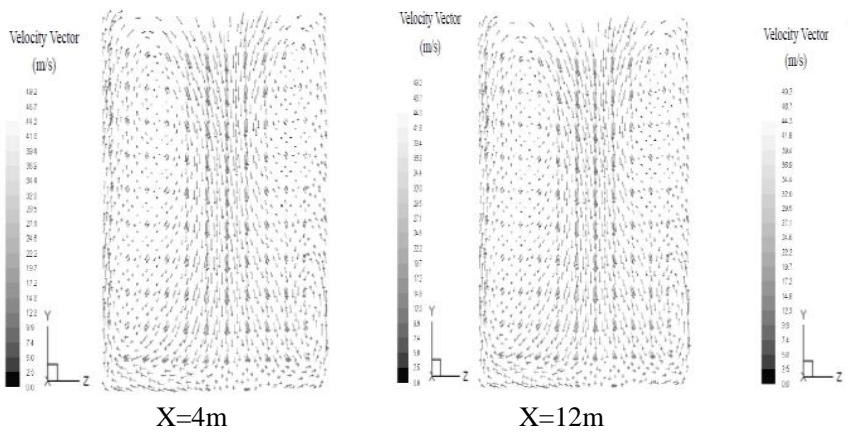

$\mathrm{B}$

Fig. 4. The velocity vector of the $\mathrm{Z}=2.85 \mathrm{~m}$ longitudinal section of different tower body width

Figure $4 \mathrm{x}=4 \mathrm{~m}$ (distance exit $1 \mathrm{~m}$ ), $\mathrm{x}=12$ (middle part), (central), $\mathrm{x}=19 \mathrm{~m}($ ), (distance exit $1 \mathrm{~m}$ ) flue gas flow field of the flue gas flow field $\mathrm{z}=2.85 \mathrm{~m}$ longitudinal section velocity vector. As shown the longitudinal section of $x=4 \mathrm{~m}$, the flue gas of the tower width A appeared the phenomenon of the wall of the flue gas impingement tower, but with the smoke moving forward, the wall of the wall was gradually weakened. The width of B tower flue gas appeared in flue gas short phenomenon in the longitudinal section of the tower. Flue gas in tower somewhere in the flow turbulence is severe, and other regional appeared "flue gas short circuit phenomenon" which is not conducive to the flue gas desulfurization. So the design of tower width $\mathrm{A}$ is in accordance with the flow field of flue gas desulfurization. This is consistent with the actual design of the site.

\subsubsection{Pressure field distribution}

Figure 5 are respectively for the tower A and B in the X-Y horizontal pressure section. As show: The upper and middle pressure distribution in the upper and middle parts of the tower wide A is more uniform, and most of the area is about 300Pa.The flue gas is running smoothly and the pressure difference between the lower part is large, which indicates that the gas flow rate is large, and the turbulent flow is relatively strong. The upper and middle pressure distribution in the upper and middle parts of the tower wide B is more uniform, and most of the area is about $200 \mathrm{~Pa}$, The pressure distribution of the lower flue gas is not uniform, the tower width A from the inlet of the tower to the middle of the absorption area of the pressure drop of about 50Pa, while the tower body $\mathrm{B}$ pressure drop value of about 150Pa.The pressure drop of the tower width A from the inlet to the absorption area is about 100Pa. 


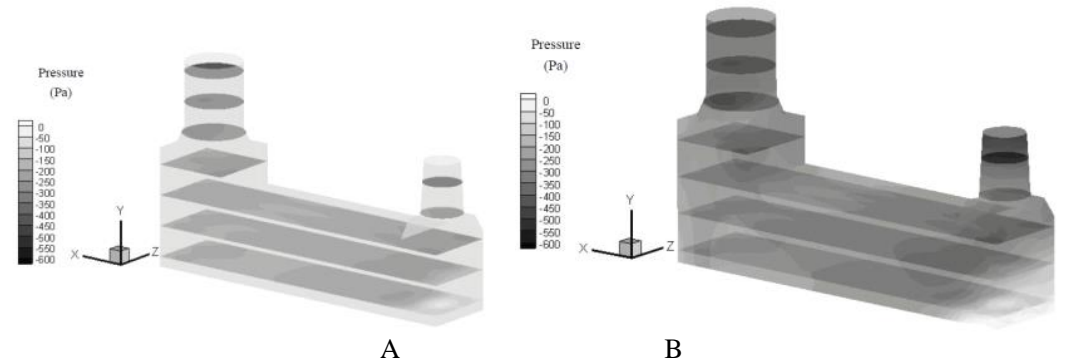

Fig. 5. X-Y transverse pressure section of flue gas in desulfurization tower

\subsection{Flow Field in Spray State}
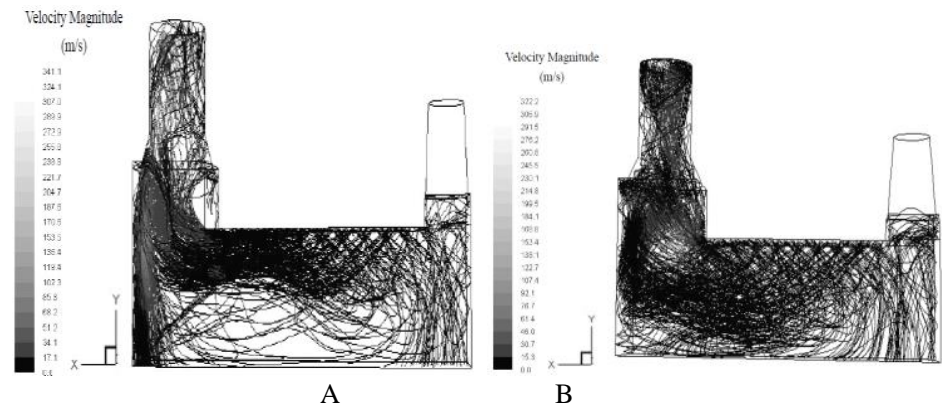

Fig. 6. Velocity distribution of spray droplets

According to the field data, in the tower from the tower at $0.1 \mathrm{M}$, arranged in 5 rows of 8 , a total of 40 spiral nozzle. The droplet spray velocity is shown in figure 6.The flue gas droplets in A are mainly concentrated in the upper part of the desulfurization tower. The droplet distribution is uniform, which is beneficial to the mixing reaction of flue gas. And the desulfurization slurry drops of B are mainly concentrated in the lower part of the tower and the outlet of the flue gas, Easy to cause "drop entrainment" influence the efficiency of flue gas desulfurization.
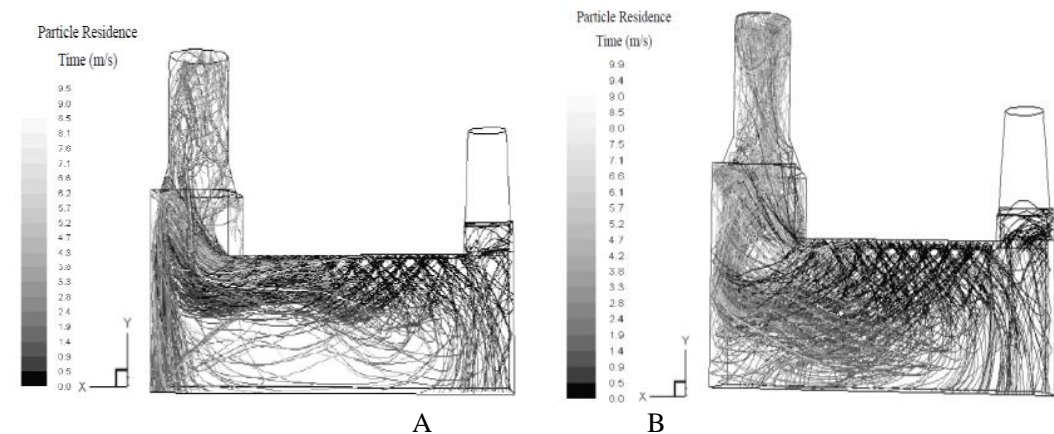

Fig. 7. Residence time distribution of spray droplets 
Droplet spray residence time is shown in Figure 7, as show: A desulfurization slurry droplet mainly in the upper tower residence time is relatively long, and is conducive to the flue gas desulfurization slurry drops full contact reaction. B desulfurization slurry droplets mainly stay at the tower body flue gas exit, it is easy to make the desulfurization slurry leakage, affecting the desulfurization of flue gas.
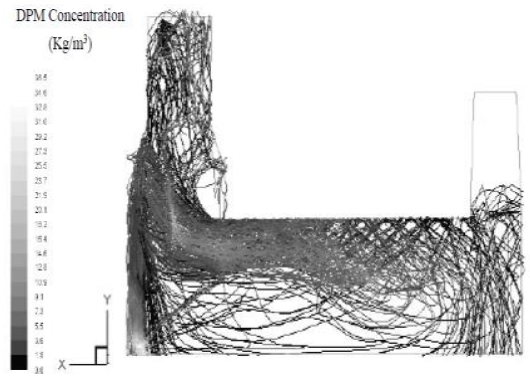

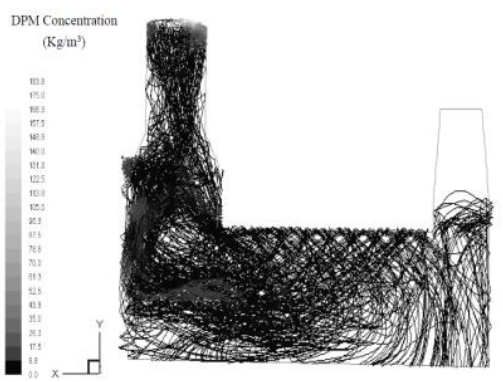

Fig. 8. Distribution of spray droplet mass fraction

Droplet spray volume fraction is shown in Figure 8, as show: A desulfurization slurry droplets are mainly distributed in the upper part of the body of the absorption region, and uniformly distributed, in favor of the droplet and gas in the large area of contact and reaction, improve utilization of desulfurization slurry rate. B the desulfurization slurry droplets are mainly distributed in the flue gas outlet, is not conducive to the full contact of the flue gas and flue gas desulfurization system, reduce efficiency in the use of desulfurization slurry.

\section{Conclusion}

Based on the analysis and discussion of the above simulation results, the following conclusions can be drawn:

1) The tower body width tower has great influence on flow field distribution, the 6.4*5.7 flow field distribution is more uniform, which is favorable for the desulfurization of flue gas.

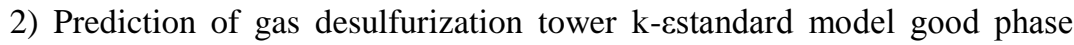
turbulent flow.

3) The discrete phase model of gas-liquid flow, to guide the practical engineering application. 


\section{References}

1. SONG Wei; YUAN Zhi-guo; LIU You-zh, etc. Research Progress of Wet Flue Gas Desulfurization Equipment. The Chinese Journal of Process Engineering, 2015,15(2):354-360

2. Ma Yiping; Xu Leping; Su Penghao, etc. Cold-state experimental comparison of seawater desulfurization between turbulent ball tower and spray tower. Chinese Journal of Environmental Engineering, 2013,7(9):3537-3542

3. Shuangchen Ma, Bin Zang, Huihui Song, Gongda Chen, Research on mass transfer of $\mathrm{CO}_{2}$ absorption using ammonia solution in spray tower, International Journal of Heat and Mass Transfer, December 2013, (67)696703

4. LI Li-qing, GUO San-xia, TANG Lin, A Study of an Innovative Swirlingflow Grid-type Desulfurizer of Flue-gases. Journal of Engineering for Thermal Energy and Power, 2007, 22(2):213-215

5. CHEN Hailin, YANG Chunping, GAN Haiming. Development and evaluation of a jet bubble reactor using vertical sieves in spiral housing as a gas inlet device for dust removal and desulfurization. Acta Scientiae Circumstantiae. 2010, 30(2):294-301

6. Chang-Keun Yi,Jae-Ek Son, Comparison of two different hot-gas desulfurization powder processes: Transport reactor and bubbling fluidized bed, Advanced Powder Technology, Volume 21, Issue 2, March 2010, Pages 119-124

7. Jeong-Hoo Choi, Chang-Keun Yi, Sung-Ho Jo, etc, A model on desulfurization characteristics of an entrained bed-bubbling bed hot gas cleanup system for IGCC, Advanced Powder Technology, Volume 22, Issue 5, September 2011, Pages 657-662

8. M. de las Obras-Loscertales, T. Mendiara, A. Rufas, L.F. de Diego, F. García-Labiano, P. Gayán, A. Abad, J. Adánez, $\mathrm{NO}$ and $\mathrm{N}_{2} \mathrm{O}$ emissions in oxy-fuel combustion of coal in a bubbling fluidized bed combustor, Fuel, Volume 150, 15 June 2015, Pages 146-153

9. ZHANG Jun-mei, ZHENG Fu-lin, DONG Ying-ying. Status Review of Mechanism Study and Equipment Development of the Liquid Column Desulphurization Technology. Petro-Chemical Equipment,2013(3):64-68

10. LI Shao-hua, SUN Ying-bo, WANG Hu. Numerical simulation analysis of the influence on temperature field by the arrangement of internal structural elements in the desulfurization tower. Journal of Shenyang Institute of Engineering(Natural Science)2013, 9(1):19-22

11. ZHU Jing, MA Qiang. Study on Flow Field of Wet Flue Gas Desulphurization Spray Tower. Boiler Technology.2011, 42(6):69-73 